\title{
Pay-What-You-Want pricing: An integrative review of the empirical research literature
}

\author{
Torsten J. Gerpott*
}

Chair of Strategic and Telecommunications Management, Mercator School of Management, University of Duisburg-Essen, Lotharstr. 65, D-47057 Duisburg, Germany

\begin{tabular}{|c|c|}
\hline CHR O N I C L E & A B S T RA C T \\
\hline $\begin{array}{l}\text { Article history: } \\
\text { Received: October 13, } 2016 \\
\text { Received in revised format: No- } \\
\text { vember } 16,2016 \\
\text { Accepted: November } 16,2016 \\
\text { Available online: } \\
\text { November } 17,2016 \\
\text { Keywords: } \\
\text { Pay What You Want pricing } \\
\text { Price setting } \\
\text { Empirical pricing research } \\
\text { Voluntary customer payments } \\
\text { Customer integration }\end{array}$ & $\begin{array}{l}\text { In a Pay What You Want (PWYW) setting companies empower their customers to fix the prices } \\
\text { buyers voluntarily pay for a delivered product or service. The seller agrees to any price (includ- } \\
\text { ing zero) customers are paying. For about ten years researchers empirically investigate customer } \\
\text { reactions to and economic outcomes of this pricing method. The present paper distinguishes } \\
\text { PWYW from other voluntary payment mechanisms and reviews } 72 \text { English- or German-speak- } \\
\text { ing PWYW publications, which appeared between January } 2006 \text { and September } 2016 \text { and con- } \\
\text { tain } 97 \text { independent empirical data sets. Prior PWYW research is structured with the help of a } \\
\text { conceptual framework which incorporates payment procedure design, buyer, seller, focal sales } \\
\text { object and market context characteristics as factors potentially influencing customer perceptions } \\
\text { of the PWYW scheme and their behavioral reactions to PWYW offers. The review discusses } \\
\text { both consistent key findings as well as contradictory results and derives recommendations for } \\
\text { future empirical PWYW research efforts. }\end{array}$ \\
\hline
\end{tabular}

(C) 2017 Growing Science Ltd. All rights reserved.

\section{Introduction}

In the recent past various types of customer-centered pricing procedures have attracted substantial attention among management researchers and practitioners. The common feature of the various "participative" price setting approaches is that they do not rely on one fixed price, which the seller unilaterally determines as valid for any buyer of a product. Rather the schemes invite customers to actively influence the prices they pay which in turn results in additional price differentiation and individualization (Gahler, 2016; Kim et al., 2009; Stegemann, 2014). One such procedure is "Pay-What-You-Want" (PWYW) pricing. It involves the complete delegation of the power to set prices to buyers in transactions that do not cover several sellers or buyers competing for the same order or offering, respectively, but concern exactly one vendor and one customer. The buyers solely decide whether, and where appropriate, how much they pay to sellers for the goods consumed. The supplier consciously agrees to accept any price set by the buyer. Consequently, the provider is not entitled to withdraw from a sale even if the customer pays nothing (i.e., a price of zero) or an amount that falls below a minimal threshold value of the seller (unknown to the customer) as in the case of the "Name-Your-Own-Price" procedure (Fay,

\footnotetext{
* Corresponding author. Tel.: +49-203/379-3109, Fax +49-203/379-2656

E-mail address: Torsten.Gerpott@uni-due.de (T.J.Gerpott) 
2004). The English-speaking literature also uses the terms "Pay What You Think It Is Worth" (El Harbi et al., 2014), "Pay What You Believe Is Fair" (Sleesman \& Conlon, 2016), "Pay As You Wish" (Bertini \& Koenigsberg, 2014), "Pay What You Like" (Fernandez \& Nahata, 2009), "Pay What You Can" (Saccardo et al., 2015) and "Pick Your Own Price" (Bourreau et al., 2015) as synonyms for the PWYW pricing method.

The PWYW procedure is a variant of "voluntary market payment mechanisms" (Natter \& Kaufmann, 2015, p. 149) that additionally encompass tipping, donations, gift giving and trust-based billing methods ("honor systems"). Five attributes listed in Figure 1 are pivotal in distinguishing the PWYW approach from the four other payment methods where buyers also independently decide on the size of their payments to suppliers. Accordingly, the PWYW method differs from the remaining mechanisms mentioned in Figure 1 through its focus on representing a financial compensation for the core instead of an ancillary product of the vendor. Furthermore, in the PWYW case customers are paying for themselves, not for others (cf. Jung et al., 2014a) and not primarily for pro-social or ethical purposes (e.g., charity). Finally, in a PWYW setting sellers do not appeal to buyers to pay a (fixed) price named beforehand in situations in which vendors do not monitor the extent to which buyers actually pay the posted "official" price (e.g., trust- or honesty-based payments for flowers, fruit, sweets or newspapers provided at unmanned points of sales; see Schlüter \& Vollan, 2015).

\begin{tabular}{|c|c|c|c|c|c|}
\hline \multirow[b]{2}{*}{ Attribute } & \multicolumn{5}{|c|}{ Payment Approach } \\
\hline & Tipping & Donation & $\begin{array}{l}\text { Gift } \\
\text { Giving }\end{array}$ & $\begin{array}{l}\text { Honor } \\
\text { System }\end{array}$ & PWYW \\
\hline $\begin{array}{l}\text { 1. Payment in direct exchange for } \\
\text { core product/service }\end{array}$ & - & - & - & $\checkmark$ & $\checkmark$ \\
\hline $\begin{array}{l}\text { 2. Payment in direct exchange for } \\
\text { ancillary service }\end{array}$ & $\checkmark$ & - & - & - & - \\
\hline $\begin{array}{l}\text { 3. Payment related to charitable } \\
\text { purpose }\end{array}$ & - & $\checkmark$ & - & - & - \\
\hline $\begin{array}{l}\text { 4. Quotation of a aspired fixed } \\
\text { price/amount by recipient }\end{array}$ & - & - & - & $\checkmark$ & - \\
\hline $\begin{array}{l}\text { 5. Strong emphasis on honesty/ } \\
\text { ethic integrity of payer }\end{array}$ & $(\mathcal{})$ & $\checkmark$ & - & $\checkmark$ & - \\
\hline
\end{tabular}

\begin{tabular}{|c|c|}
\hline Legend & $\mathcal{J}=$ Yes \\
\hline
\end{tabular}

Fig. 1. Profile of voluntary payment mechanisms in commercial transactions on moral markets

The literature is rather mixed in assessing the degree of novelty of the PWYW idea and its dissemination in management practice. The majority of the authors claim that the method is "innovative" (Schons et al., 2014, p. 26). In contrast, a few contributions take the opposite view that PWYW pricing is "neither novel nor uncommon in practice" (Stegemann, 2014, p. 3) because cultural institutions (e.g., museums) and street artists have resorted to this approach for a long time and because the authors believe that a considerable number of firms from a broad range of industries is already using the PWYW method (Mak et al., 2015; Natter \& Kaufmann, 2015; Stegemann, 2014).

At first glance, the supply of goods under PWYW conditions is inconsistent with classical economic theory because according to its predictions purely selfish buyers would always take products without 
paying any money with the outcome that sellers inevitably suffer losses. However, noting that customers do not only incur monetary but also social, psychological or moral transaction costs on markets (e.g. perceived lack of fairness, social or self-image concerns) it may be "rational" or "profit maximizing" for buyers to pay prices $>0$ when facing PWYW offerings (Gneezy et al., 2012; Lee et al., 2015; Natter \& Kaufmann, 2015; Santana \& Morwitz, 2013). In a similar vein, suppliers may rate an introduction of the PWYW method as being commercially advantageous for them because they expect that its use will improve the awareness for their offerings and their overall image among potential customers. These effects in turn, may increase the sales volume or the average unit price for goods sold under PWYW conditions or other products offered at conventional fixed prices (Kim et al., 2010b; Riener \& Traxler, 2012).

Against the background of such potential benefits of PWYW pricing plans it should not come as a surprise that meanwhile, there is a considerable number of scholarly empirical PWYW studies mainly authored by economists and psychologists. In the face of the significant and quickly growing volume of research on PWYW pricing several authors have already tried to summarize the available evidence (Greiff \& Egbert, 2016; Natter \& Kaufmann, 2015; Pöyry, 2015; Stegemann, 2014). Unfortunately, the previous reviews consider much less than half of the relevant publications and omit important subject areas of empirical work on PWYW pricing. Hence, a full review of the empirical PWYW literature is still missing. Therefore, the present paper's objective is to provide a comprehensive conceptual framework for structuring the main thematic areas covered in empirical PWYW studies and to use the framework to organize and discuss the relevant findings, to identify research gaps and derive overall implications for PWYW applications in practice. For researchers in the fields of consumer behavior and pricing such a review ought to be valuable because it provides them with a quick to read overview of the state of empirical knowledge on the PWYW approach. In addition, management practitioners should benefit from a research summary, which derives clues for a better design of PWYW pricing in corporations and other types of organizations.

The article is structured as follows. Firstly, section 2.1 explains the procedures to identify and select empirical PWYW contributions for the present review. Then, section 2.2 reports descriptive statistics with regard to method characteristics of the investigations which are pivotal to the summary. Section 2.3 develops a conceptual framework organizing the subject fields addressed in PWYW studies. In section 3 we use this framework to summarize the empirical evidence on factors significantly influencing the acceptance of PWYW offerings and voluntary payment amounts at the level of the individual consumer. Section 4 discusses findings concerning customer perceptions of PWYW price plans. Section 5 analyzes empirical work containing evaluations of the business effects of PWYW pricing at the organizational level. Finally, in section 6, we conclude with general implications for future PWYW research and overarching notes regarding conductive conditions and design principles for practical PWYW applications.

\section{Identification, method profile and systematization of empirical PWYW evidence}

\subsection{Study identification and selection procedures}

To identify empirical PWYW work published either in English or in German as comprehensively as possible, we supplemented an initial Google scholar search by scanning the following online (meta-) databases of commercial and non-profit publishers and information brokers: EBSCOhost (including EconLit, PsycINFO, Sociological Collections), Elsevier (Science Direct, Scopus), Emerald, Inderscience, JSTOR, ProQuest (inter alia Sociological Abstracts), PubMed, Sage, Springer, Web of Science and Wiley. The keywords "pay what you want/can/like/think it is worth/wish", "innovative/ participative pricing" and "voluntary payment" served as starting points. Identified publications were checked for potentially relevant, previously unknown references. We concluded our search on 30th September 2016. 
Then we refined the selection to leave only papers that contain empirical PWYW pricing analyses based on self-collected data. In doing so, we classified three research streams as not being directly relevant and excluded each of them from the in-depth analysis. Firstly, all contributions developing microeconomic models mainly to work out preconditions for generating seller profits from PWYW offers were eliminated if they did not contain tests of the validity of their model with empirical primary data. Accordingly, our review does not count, for instance, the articles of Chao et al. (2015), Greif et al. (2014), Isaac et al. (2015), Kahsay \& Samahita (2015) or Tudón (2015) as empirical contributions. Secondly, empirical work on tipping, donations, customer gifts and trust-/honor-based billing variants was not included, because these four voluntary market payment mechanisms differ in terms of important attributes from the PWYW price setting approach (see Figure 1). Apart from that, excellent research reviews for these participative, voluntary payment procedures are already available (Azar, 2007; Bekkers \& Wiepking, 2011; Natter \& Kaufmann, 2015; Schlüter \& Vollan, 2015). Thirdly, we excluded laboratory studies of so-called "dictator games" in which individuals act as payers or recipients of money (see the reviews of Engel, 2011; Mousazadeh \& Izadkhah, 2015). The reason for this elimination is that the payment situations artificially created in this type of experimental research differ fundamentally from PWYW pricing, because payments in such games are not linked to the purchase and sale of any good.

As a result, the present synopsis focuses on academic empirical primary studies, which each look at a larger number of PWYW transactions and either explore correlates of the level of prices determined independently by buyers or compare behavioral reactions of customers confronted with the PWYW method with those observed in case that other pricing setting mechanisms are in place. Hence, the limited set of studies that merely report distributions of PWYW prices in a sample of transactions (e.g., Chen \& Liang, 2014; Lynn, 1990; Steiner, 1997) is only of marginal importance for this review. The application of the criteria described above resulted in the inclusion of 72 empirical PWYW studies, which contain 97 independent data sets and were published between 2006 and 2016, in our substantive detailed analysis. The reference list of the present paper marks these 72 sources by an asterisk.

\subsection{Profile of the methods of the reviewed studies}

This section profiles the methodological design of the 97 data sets under review in terms of the following five attributes: (1) sample size, (2) type of study subjects/buyers (student or non-student customers), (3) type of transaction situation and of payment measures associated with the situation (field study of real payment behaviors or fictitious/hypothetical intentions to pay according to questionnaire responses), (4) temporal structure of the data collection and analysis and (5) category of goods sold under PWYW conditions.

The total number of PWYW transactions covered in those 96 studies reporting sample size statistics amounts to $30,634,507$. Of this total, $98.7 \%$ are attributable to the two investigations of Bourreau et al. (2015), who studied sales data of music albums, and of Gneezy et al. (2010), who gathered PWYW data of roller coaster customers offered a photo taken during their ride. Leaving these two studies aside, the overall number of PWYW transactions in the remaining 94 data sets is 407,131 . The number of transactions underlying an analysis varies between 22 and 81,641. 16.0\% of the datasets include less than 100 purchases, $46.8 \%$ between 100 and 499 cases, $16.0 \%$ between 500 and 999 transactions, $11.7 \%$ between 1,000 and 9,999 purchases and $9.5 \%$ at least 10,000 . The median of the number of transactions per data set is 355 .

$46.4 \%(53.6 \%)$ of the 97 data sets use samples in which the majority of the subjects are students (no students). 96 studies indicate whether they investigate (a) a fictitious/hypothetical purchase and therefore captured payment amounts as intentions to pay stated in a questionnaire or (b) a real transaction in the field and consequently captured payment amounts in the form of actual behaviors observed by 
technical systems or documented in retrospective reports from the buyers. $36.5 \%(63.5 \%)$ of the data sets analyze hypothetical (real) purchases/payments. In the subset of 44 investigations reporting payment amount statistics and using mainly students the share of studies based on fictitious purchase scenarios and claimed intentions to pay is $45.5 \%$. This proportion is marginally higher than the corresponding share of $28.8 \%$ found in 52 PWYW data sets, which include real transactions in buyer samples not primarily composed of students $\left(\left(\chi^{2}=2.84 ; \mathrm{df}=1 ; \mathrm{p}<0.09\right) .20 .8 \%\right.$ of the total of 96 studies, which provide information on the two aforementioned method attributes can be classified as very problematic in terms of their methodology because they analyze hypothetical buys of students. The first reason for this evaluation is that they are limited to a buyer group for which the extent to which they allow to derive valid conclusions with regard to "normal consumers" is highly controversial. The second reason is that they rely on hypothetical prices and intentions to pay, respectively, which are highly likely to exceed the corresponding amounts in case of real transactions (Gahler, 2016; Jung et al., 2016; Kim et al., 2014a; Kunter \& Braun, 2013).

$94.8 \%$ of the 97 studies refer to one point in time and are therefore cross-sectional. Reversely, $5.2 \%$ of the investigations are truly longitudinal and capture developments of the level of PWYW prices for a category of goods over time at the overall sample level or intraindividual changes in voluntary payments under PWYW conditions. In addition, two cross-sectional analyses report supplementary qualitative evidence on variations in the mean PWYW amounts over time.

The most frequently studied categories of goods are food and beverages offered by service providers (e.g., restaurants, bars) for immediate consumption. This category is covered in 42 data sets. Various other service categories (e.g., museum, concert, cinema, sport event, flight, hotel overnight, fitness studio) are the focus of 24 investigations and therefore make up the second most studied category of goods. 20 investigations deal with a broad variety of physical goods mostly sold at low absolute prices (e.g., printed book, photo, music CD, DVD, mobile phone, wet razor, coffee mug, grocery bag). Finally, 19 studies are concerned with goods offered in digitized form (e.g., newspapers, books, games, music albums, software). Overall, the survey of the product and service categories covered so far in PWYW investigations suggests that researchers tacitly assume the following: PWYW pricing primarily comes into question to sell (gastronomical) services or digitized products for which free production capacities are at hand, which generate low absolute variable costs and where - from the perspective of an average consumer - purchases at a standard (fixed) market price do not require a considerable willingness to make financial sacrifices.

\subsection{Conceptual framework for structuring key themes covered in the reviewed studies}

The various research topics addressed in the reviewed 72 PWYW publications/97 PWYW data sets can be organized with the help of the conceptual framework shown in Figure 2. Roughly, the thematic fields of empirical PWYW studies incorporate three main streams. Firstly, a large number of studies are concerned with variables that are interpreted as factors potentially influencing the level of the prices paid voluntarily by customers or other significant economic effects of the PWYW price setting method (e.g., take-up/purchase rate of offers, seller image). These "success factors of PWYW pricing" (Stegemann, 2014 , p. 19) can again be subdivided into five classes, namely characteristics of (1) the design of PWYW procedure, (2) the buyers, (3) the sellers, (4) the focal sales objects and (5) the market context. Investigations within the first main stream implicitly apply the "stimulus-response-paradigm" as they do not directly consider buyer perceptions of the PWYW pricing method. Secondly, a much less voluminous stream of studies follows the "stimulus-organism-response-paradigm" by exploring correlations between each of the five five classes of factors listed above and buyer perceptions of various features of the PWYW method applied as well as between such perceptions and criteria reflecting effects of the use of the PWYW price setting approach at the level of the individual consumer (e.g., prices paid, (re-)purchase rates). Within the third research stream, the particular emphasis is on evaluations of 
the success or outcomes of PWYW pricing applications. The assessments especially include criteria measured at the company level and thereby surpass individual customer/micro level investigations.

The subsequent sections 3 to 5 discuss the findings, which can be derived from each of these three streams of empirical PWYW research.

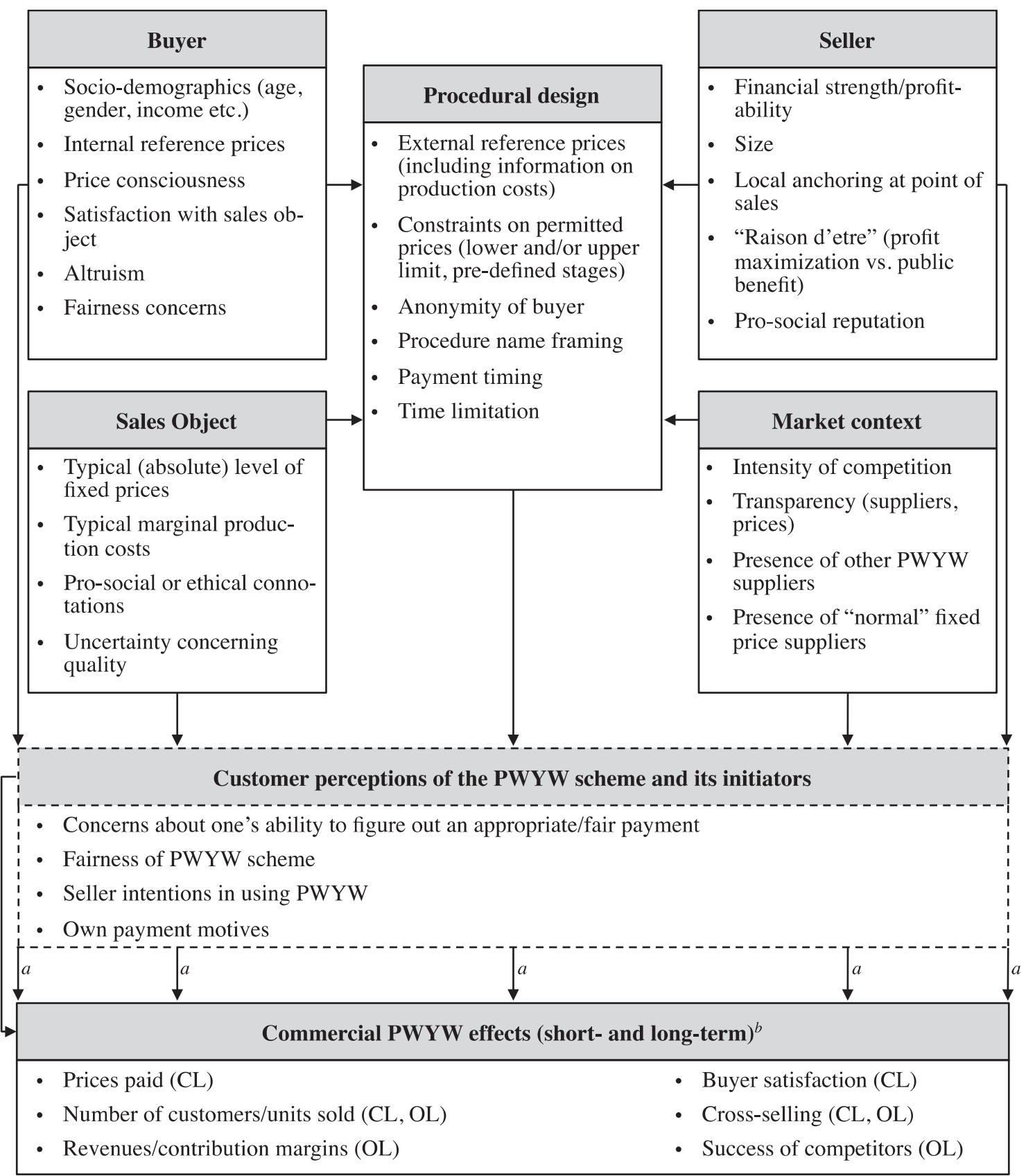

a) Direct success effects of variable blocks procedural design, buyer, seller, sales object and market context according to stimulus-response paradigm.

b) Impact criteria can be measured at the micro/customer level (CL), the macro/organizational level (OL) or both at the CL and OL.

Fig. 2. Conceptual framework of the most important variable categories and interconnections in the PWYW research field 


\section{Factors influencing individual-level outcomes of PWYW pricing}

\subsection{Design characteristics of the PWYW procedure}

As can be seen from Figure 2, we extracted six features of the PWYW method itself, which suppliers can deliberately shape and which were taken up in past investigations. According to Table 1, by far the most frequently researched design characteristic is the use and construction of information on reference prices $(R P)$. This feature is about price nominations made by suppliers (external $R P$ ) or recalls from buyers' memories with regard to prices that they have observed or paid for similar goods in the past (internal RP) (cf. Mazumdar et al., 2005). As internal RP are not directly malleable by suppliers, they do not constitute a PWYW design feature but a buyer characteristic, which is discussed in section 3.2.

\subsubsection{External reference prices}

External RP can be introduced by sellers in the form of an obligatory minimum price, which buyers are not allowed to undercut (Thomas \& Gierl, 2014). Furthermore, suppliers have the option to provide customers with a small number of predetermined tiered prices and to ask them to select the price level they want to pay (Lynn, 1990). Finally, sellers can not only quote lower but also upper price limits, which customers are not entitled to overbid (Johnson \& Cui, 2013; Jung et al., 2016; Regner, 2015; Regner \& Barria, 2009; Regner \& Riener, 2012). A commonality underlying the three variants of binding external RP is that they consistently imply a considerable dilution of the central idea of the PWYW method according to which seller price recommendations or pressures are undesired to ensure that buyers are really free in their decision on which amount they pay.

Instead of binding external RP, suppliers can revert to various types of less restrictive price nominations. Such prices can have a normative frame ("we recommend that you pay <...>"). Alternatively, sellers have the option to provide descriptive information on their fixed prices in the recent past or amounts that other buyers have paid for the same good under PWYW conditions (Armstrong Soule \& Madrigal, 2015; Johnson \& Cui, 2013; Jung et al., 2016; Krawczyk et al., 2015). The violation of the aforementioned fundamental PWYW principle of an unrestricted freedom of consumer price choice is less serious in cases, where sellers use non-binding external RP compared to situations in which binding external RP are quoted.

The bulk of the literature emphasizes that external RP act as anchor points reducing consumer uncertainty with respect to an "appropriate" or "fair" price, because buyers can use them to calibrate their PWYW price setting decisions. Accordingly, higher levels of external RP provided by sellers should lead to higher payment amounts. Similarly, PWYW sales accompanied by external RP should result in higher payments relative to offers that are not supplemented by external RP nominations. The majority of the empirical PWYW studies, which analyze external RP, support these suppositions (Armstrong Soule \& Madrigal, 2015; Gautier \& Van der Klaauw, 2012 (in case of incidental customer encounters with PWYW offers); Jang \& Chu, 2012; Jung et al., 2016 (in case of hypothetical payments); Kim et al., 2014a; Krawczyk et al., 2015; Lee et al., 2011, 2015; León et al., 2012; Parvinen et al., 2013; Perfecto et al., 2013; Perfecto et al., Pöyry \& Parvinen, 2014; Pöyry et al., 2013; Regner \& Barria, 2009; Riener, 2008). Furthermore, several PWYW studies, in which customers were provided with information on the variable production costs of the goods offered, find significantly positive correlations between the level of the stated direct costs - which can be regarded as a special variant of external RP - and the level of voluntary customer payments (Jang \& Chu, 2012; Kim et al., 2014a; Krämer et al., 2015; Schmidt et al., 2015; for an insightful theoretical analysis of this association see Greiff et al., 2014). In light of these results, it is not surprising that earlier reviews of the empirical PWYW literature summarize the state of the evidence as follows: "the provision of external reference prices in the form of a regular or suggested price usually has a positive impact on the prices paid [voluntarily]" (Stegemann, 2014, p. 33; for similar summaries see Gahler, 2016, p. 31; Pöyry, 
Table 1

Significance and direction of variable associations in PWYW studies ${ }^{\mathrm{a}}$

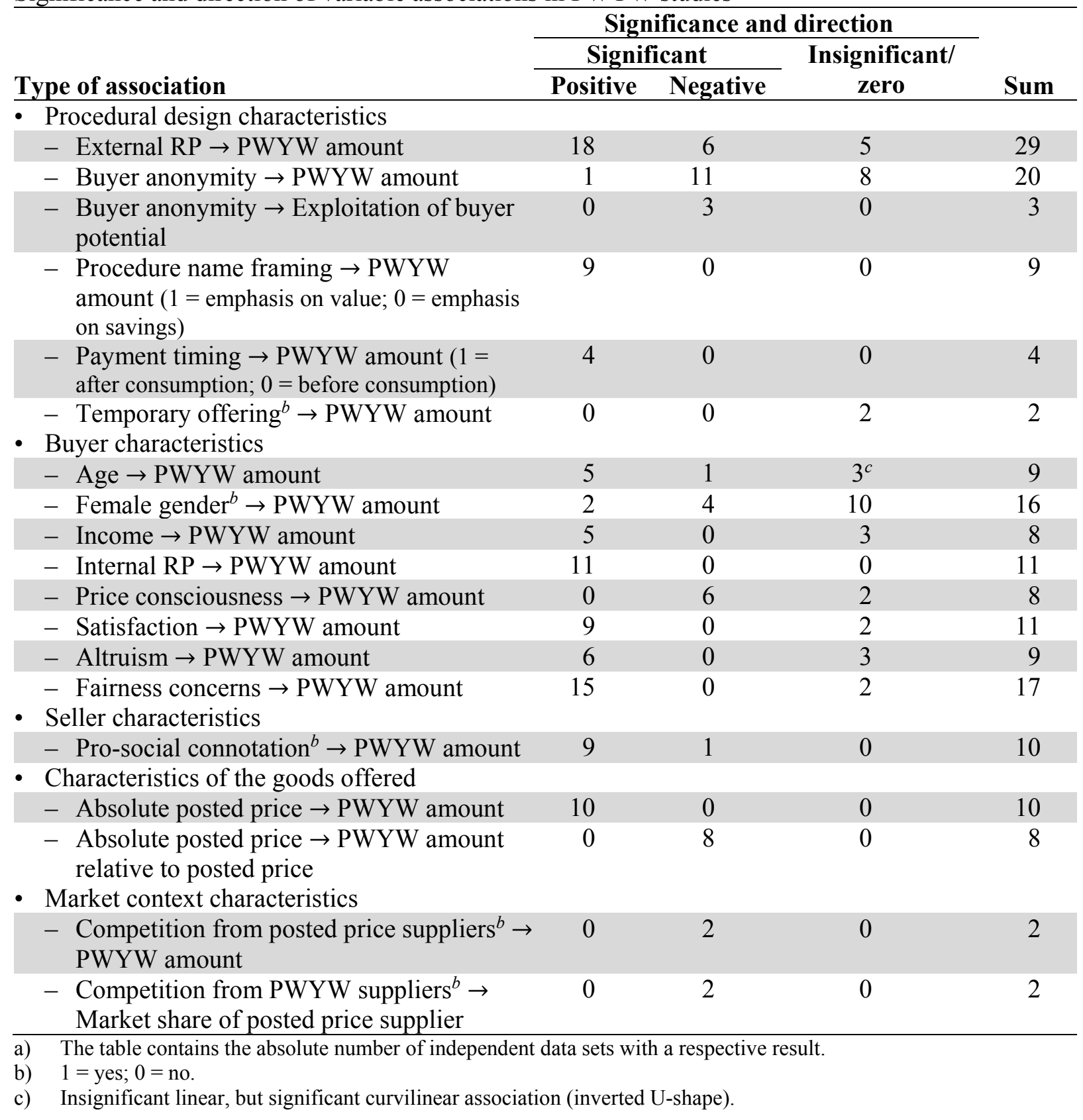

2015, p. L-28). However, there are strong empirical and conceptual reasons to suggest that this conclusion is immature.

Firstly, the cited conclusion neglects the results of several PWYW studies, which detect no significant associations between the level or the use of external RP and prices paid (Gautier \& Van der Klaauw, 2012 (in case of self-selected PWYW participation of customers); Gneezy et al., 2012; Hildenbrand et al., 2016; Jung et al., 2016 (in case of field studies on actual prices paid); Weisstein et al., 2016) or even find significantly negative correlations, particularly if the external RP was displayed as a minimal threshold value (Johnson \& Cui, 2013; Jung et al., 2016 (study 12a); Kunter \& Braun, 2013; Racherl et al., 2011; Roy et al., 2016a; Thomas \& Gierl, 2014). Secondly, it ignores that significantly positive effects of external RP are mainly observed in studies which are highly problematic in terms of their methodology, because they focus on hypothetical payments of students, whereas field studies of real 
purchases almost never report such effects (Jung et al., 2016, p. 356). Thirdly, it does not take note of conceptual arguments according to which buyers may perceive the addition of external RP to PWYW offers as an illegitimate attempt to influence their payment as well as an undesired limitation of their discretion in setting their own prices and who therefore may react negative to such cues (Racherla et al., 2011).

In conclusion, the overall present state of the empirical evidence suggests that external RP effects on the level of PWYW prices paid are not consistently positive but depend on additional situational constraints (see also Greiff \& Egbert, 2016, p. 6). Therefore, future PWYW research should concentrate less on exploring bivariate associations between the use or the level of external RP on the one hand and voluntary payment amounts on the other. Rather, as similarly proposed by Natter \& Kaufmann (2015), a more seminal approach would be to analyze how external RP effects are moderated by other features of the PWYW design (e.g., anonymity of buyers), the goods sold (e.g., novelty), the buyers (e.g., price knowledge) and the seller (e.g., pro-social reputation). Three such potential moderators have already received some attention in the PWYW literature:

- Anonymity of buyers: This variable may moderate external RP effects in the following way: In circumstances where buyers do not pay anonymously, they experience heavier social pressure as a result of which they should be more inclined to put a greater weight on external RP in choosing a voluntary payment amount. Conversely, if buyers remain unobserved or anonymous during the payment process, they should be less guided by external RP and more by other considerations or constraints (e.g., fairness concerns) in setting their level of payment (Gahler, 2016; Gneezy et al., 2012; Pöyry et al., 2013; Riener, 2008; Roy et al., 2016a).

- Availability of internal RP among buyers: If buyers are able to memorize an internal RP, it should be easier for them to develop a sense of an "adequate" level of payment on their own. Consequently, effects of external RP are likely to be stronger if buyers lack internal RP, for instance, because the offered goods are new to them or do not trigger a high personal involvement (Kunter \& Braun, 2013; Schröder et al., 2015).

- Fairness of external RP: If customers are convinced that the external RP quoted by sellers are fair, credible or plausible in the sense that they reflect standard fixed prices currently charged for the focal good in the relevant market or average PWYW amounts paid by other buyers or the good's direct production costs with sufficient precision, then the external RP level should have positive impacts on offer acceptance rates and voluntary payment amounts. However, in a situation, in which buyers perceive external RP as being unfair, implausible, extreme outliers and not cost-oriented, such external RP effects should be absent or even become negative (Gautier \& Van der Klaauw, 2012; Greiff \& Egbert, 2016; Johnson \& Cui, 2013; Jung et al., 2016; Kim et al., 2014a; Krawczyk et al., 2015; León et al., 2012; Weisstein et al., 2016). Fairness perceptions of external RP under PWYW conditions should, in turn, to a large extent depend on the image of sellers from the perspective of buyers (see below section 3.3).

Apart from the very limited analysis of factors potentially moderating the impacts of external RP on the level of prices paid voluntarily, the present review reveals a second research gap in connection with external RP in a PWYW context: Past studies have focused on external RP effects on voluntary payment levels. For this reason, there is a dearth of research on external RP effects on other equally important business outcomes. However, empirical findings of Jung et al. (2016; study 2) and microeconomic modelling results of Kahsay \& Samahita (2015) suggest that as external RP provided by suppliers rise, an increasing share of consumers avoid buying from them and instead either purchase the product concerned from competitors who sell it at (lower) market standard fixed prices or completely refrain from buying it. Therefore, future research in the PWYW field should extend its outcome measures in the direction of additional business-relevant criteria, such as the number of customers or the ratio of persons who buy a product under PWYW conditions to all persons who have the possibility 
to accept a PWYW offering or the seller's image in the eyes of buyers (cf. Natter \& Kaufmann, 2015, p. 152).

In terms of implications for price setting in practice, the review results indicate that suppliers should not name lower PWYW payment boundaries which are well below standard market prices for the relevant product or which define minimal mandatory payment amounts. Such lower thresholds incentivize buyers to deemphasize their own internal RP if it falls above the sellers' external RP, and to give more weight to the (low) external RP communicated by the supplier in choosing the price they wish to pay. Furthermore, the provision of external RP in a PWYW process should, at best, be financially advantageous for sellers if they offer goods which are quite unknown to potential buyers and for which the latter have no clear ideas with regard to currently charged market prices or variable production costs and if they place a high level of trust in prices named by their supplier (e.g., because of a long business relationship). If these three situation characteristics are absent, then the state of research suggests that the sellers' cost-benefit-balance of providing external RP is likely to be negative because the PWYW scheme deters potential customers from buying at all. Consequently, under these circumstances suppliers are probably well-advised to make PWYW offers without the provision of external RP.

\subsubsection{Buyer anonymity}

This PWYW feature reflects whether supplier representatives or other persons, who are more or less personally acquainted with the buyers, are physically present when and therefore are in a position to note the amounts customers are paying. If other human beings are around and observe the payments of buyers, then the PWYW design is non-anonymous, otherwise the process is anonymous. The vast majority of PWYW studies argue that a non-anonymous PWYW procedure increases the "normative influence of social environments (Stegemann, 2014, p. 34) on customers to pay a "fair" price (e.g., Armstrong Soule \& Madrigal, 2015; Dorn \& Suessmair, 2016; Machado \& Sinha, 2012). Consequently, the average PWYW price paid should be higher, if buyers are not anonymous compared to situations in which buyers' personal identity remains undisclosed. In contrast to this, a smaller number of authors emphasize that the average prices paid are unlikely to differ as a function of buyer anonymity. The explanation given for a missing anonymity effect is that anonymous customers also strive to keep a positive self-image by not treating a supplier unfair. This has the consequence that anonymous buyers do not pay lower prices than their non-anonymous counterparts (Gneezy et al., 2012; Jang \& Chu, 2012).

The empirical results obtained to date (see Table 1) predominantly indicate that buyer anonymity decreases the average amount paid in PWYW settings (Bondos \& Lipowski, 2016; Dorn \& Suessmair, 2016; Hilbert \& Suessmair, 2015; Kim et al., 2014a (study 1); Lee et al., 2015; Machado \& Sinha, 2012; Pöyry \& Parvinen, 2014; Riener \& Traxler, 2012; Santana \& Morwitz, 2011, 2013; Veit \& Ammermann, 2013). However, the negative effects are primarily reported in studies of hypothetical intentions to pay in student samples whose validity is highly questionable. Furthermore, some researchers find no or even significantly positive effects of buyer anonymity on the mean of the prices paid under PWYW conditions (Gahler, 2016; Gneezy et al., 2012; Kim et al., 2014a (study 2); Park et al., 2016; Parvinen et al., 2013; Regner \& Riener, 2012; Riener, 2008; Roy et al., 2016a; Saccardo et al., 2015).

Moreover, the analysis of Regner \& Riener (2012) provides strong evidence suggesting that many potential customers perceive a non-anonymous PWYW process as unpleasant, restrictive and disconcerting. The result of this negative evaluation is that in non-anonymous contexts a much larger share of

prospective customers is completely deterred from buying from PWYW suppliers than in situations in which buyers remain anonymous. This "deterrence proposition" also receives support in field studies of actual non-anonymous PWYW purchases conducted by Gneezy et al. (2012) and Jung et al. (2014b).

The studies according to which non-anonymous PWYW procedures come along with strong customer self-selection effects also suggest that future research should no longer look only at anonymity effects 
on the prices paid in samples of consumers who did not deliberately opt for or against purchases in a PWYW setting but who were simply unable to circumvent them because the researchers' data generation set-ups forced them into such transactions. Instead, the distribution of voluntarily paid prices should be specifically examined in subgroups of consumers, who completely voluntarily decided to enter into a PWYW context. In this regard the results of Gautier \& Van der Klaauw (2012) and León et al. (2012) reveal that even in the case of self-selected participants a non-anonymous PWYW design leads to significantly lower payments than an anonymous approach. These studies argue that a nonanonymous process mainly attracts consumers who look for a bargain relative to standard fixed prices (Kunter, 2015) and therefore are even prepared to disclose their identity. Furthermore, it is desirable to improve the explanatory power of studies on effects of buyer anonymity in PWYW settings by including additional moderators in the analysis. Two such potential key moderators are the degree to which (1) (non-)anonymous payments for the specific category of goods under study are customary under "normal" fixed price conditions and (2) PWYW buyers accept an offering because they value the high level of participation in setting prices or because of the possibility to obtain a good at a low price (type of PWYW motivation).

In practice, the current state of evidence implies that PWYW processes are more acceptable for consumers when buyers can pay without being directly observed by the supplier or other persons. In case of a non-anonymous PWYW procedure with a high visibility of the amount paid to other parties, there is a high probability that many prospective buyers are dissuaded from a transaction and that the remaining customers are characterized by a low willingness to pay.

\subsubsection{Other design features}

Apart from the two PWYW design features discussed above, there are three other procedural PWYW attributes that have been repeatedly included in the relevant empirical literature.

Firstly, researchers have explored framing effects, which are caused by the procedure name chosen to introduce PWYW offerings, on the prices paid (see Table 1). Atlas (2015) finds higher voluntary payments if consumers are asked to choose a rebate on the fixed price compared to the standard PWYW framing. Machado \& Sinha (2012) detect significantly higher average payment amounts if the procedure was called "Pay What It Is Worth To You" compared to a presentation under the name PWYW. Saccardo \& Gneezy (2014) and Saccardo et al. (2015) observe that the levels of voluntary payments were significantly higher if the price setting approach was addressed with the heading "Pay What You Can" or "Donate What You Want" than if it was labeled as PWYW. Schröder et al. (2015) find that naming the procedure as "Reduce The Price As Much As You Can" resulted in significantly lower payments than presenting it as PWYW. Sleesman \& Conlon (2016) report significantly higher payments if the name framing is "Pay What You Believe/s Fair" instead of PWYW. Taken together the six studies and their nine data sets point in the direction that the prices paid in PWYW contexts can be positively influenced by presenting name frames that emphasize the value of the goods offered or the financial standing of the buyers instead of saving opportunities triggered by this price setting approach.

The second other design feature relates to the "timing" of the voluntary payment before or after the consumption of the goods purchased (see Table 1). Four pieces of research contain indications that voluntary prices paid are higher in situations where buyers pay after they have already consumed or tried out the goods offered in a PWYW context than in cases where buyers first decide about their payment amount and then consume a service or receive the product they purchased (Drevs, 2013; Kim et al., 2014a; Machado \& Sinha, 2012; Regner, 2015). An explanation for these differences in the amounts paid is that paying after service consumption or product trials reduces information asymmetries favoring sellers over buyers particularly in case of experience goods (Greiff et al., 2014). Of course, the positive effects of ex-post payments compared to paying in advance are the larger, the more customers are satisfied with the services or products they purchase (see section 3.2.4). Consequently, 
practitioners would be well-advised to prefer an ex-post price setting approach over an ex-ante timing if it is very likely that customers positively evaluate the goods which they buy.

The third design characteristics analyzed is whether a PWYW offering is temporary or not (see Table 1). Kim et al. (2014a) and Parvinen et al. (2013) both find that the level of prices paid is not significantly affected by whether sellers communicate to prospective buyers that their PWYW offer is a temporary sales promotion measure or a pricing approach of indefinite duration.

\subsection{Buyer characteristics}

Figure 2 and Table 1 reveal that the following attribute classes of buyers have attracted greater attention in the empirical literature: (1) Socio-demographic variables, (2) internal RP, (3) price consciousness, (4) satisfaction with the purchased goods and (5) general social preferences. Subsequently, we summarize pertinent empirical results for each of the variable categories.

\subsubsection{Socio-demographic variables}

Age, gender and income are the most frequently studied socio-demographic correlates of payment amounts for PWYW goods. Investigations on age effects contain mixed results. Five studies identify significantly positive interrelations between age and PWYW prices (Borck et al., 2006; Kim et al., 2014a; León et al., 2012; Racherla et al., 2011; Waskow et al., 2016). Regner (2015) finds a negative association, whereas research of Gautier \& Van der Klaauw (2012), Gneezy et al. (2012) and Riener (2008) suggests an inverted U-shaped pattern.

Research results with regard to gender differences in voluntarily paid prices are also heterogeneous. Borck et al. (2006) and Saccardo \& Gneezy (2014) discover that females pay more than males. Four other analyses contain opposite results (Gautier \& Van der Klaauw, 2012 (in case of self-selected PWYW participants); Kim et al., 2014a (study 1); Schröder et al., 2015; Waskow et al., 2016). Ten publications report no significant gender impact on prices paid (Gahler, 2016; Gautier \& Van der Klaauw, 2012 (in case of incidental encounter with PWYW offering); Gneezy et al., 2012; Kim et al., 2014a (study 2); Rachelor et al., 2011; Regner, 2015; Regner \& Barria, 2009; Riener, 2008; Roy, 2015; Roy et al., 2016a).

Empirical evidence on effects of buyer income on voluntarily paid amounts in PWYW settings is a little less diverging. Five studies indicate that the association between the two variables is significantly positive (Kim et al., 2009, 2014; Mills, 2013; Regner, 2015; Riener \& Traxler, 2012). Three investigations observe an insignificant correlation (Borck et al., 2006; Roy, 2015; Roy et al., 2016a), but the validity of two of the three null-result-publications is low because they examine student samples with restricted income variances.

Faced with the inconclusive evidence with respect to associations between socio-demographic buyer characteristics and prices paid in a PWYW context, one may be tempted to argue that additional studies with a focus on this class of variables are required to better understand the reasons behind the mixed findings. However, such research endeavors will only achieve greater scholarly importance if they more extensively draw on theoretical frameworks explaining socio-demographic effects by explicitly dealing with the psychological and economic phenomena for which socio-demographic variables are just proxies. In practice, the results summarized in this section imply that managers should refrain from trying to target PWYW offerings to consumer subgroups defined by means of a specific socio-demographic profile because such an approach is unlikely to increase the average amount paid voluntarily per customer. 


\subsubsection{Internal reference prices}

Internal RP are price benchmarks retrieved from buyers' memories which customers rate as adequately reflecting normal market prices or which they have already paid in the past for a similar offering or for which they assume that such prices have already been paid by other individuals in the focal PWYW setting (Roy, 2015). The PWYW literature takes the view that internal RP help buyers to derive the amount they want to pay voluntarily. Thus, the correlation between the two variables should be positive (Stegemann, 2014). Without exception, the available empirical evidence is in line with this hypothesis (see Table 1). Results are affirmative regardless of whether internal RP are measured as a memorized amount which buyers had paid for comparable offerings under fixed price conditions (Mills, 2011, 2013; Roy, 2015; Roy et al., 2016a, 2016b; Schons et al., 2014) or as the presumptions of buyers with respect to the typical amount paid by other persons for a similar good (Borck et al., 2006; Gneezy et al., 2012; Kunter \& Braun, 2013; Machado \& Sinha, 2012). The clarity of the internal RP findings combined with the ambiguity of the pertinent results for external RP (see section 3.1.1) suggest the following proposition to be tested in future research: Due to the higher credibility of internal compared to external RP, internal RP have a positive impact on voluntary payments in PWYW settings, which is significantly stronger than the effect of external RP.

The internal RP results also have important implications for setting PWYW prices in practice. They indicate that an identification of buyer groups characterized by high internal RP should be an effective lever to increase the amounts paid. However, the positive financial consequences of such a strategy are limited by the boundary condition that positive internal RP effects on prices paid become the smaller, the larger the absolute values of standard market prices of the PWYW goods are (see section 3.4 below).

\subsubsection{Price consciousness}

This buyer characteristic refers to the weight consumers assign to low prices when making purchasing decisions (Kim et al., 2009). The general notion is that buyers' price consciousness significantly negatively affects PWYW prices paid. Six studies contain indications supporting this position (Kim et al., 2009; Kunter, 2013; Marrett et al., 2012; Mills, 2013; Roy et al., 2016b; Schons et al., 2014). According to findings of Roy (2015), the effects of price consciousness are moderated by the internal RP of buyers: Price consciousness has the expected negative effect on the amount paid if buyers' internal RP is high, but not in case of low internal RP. Finally, Drevs (2013) and Kim et al. (2014a) observe insignificant correlations between price consciousness and PWYW prices paid. On balance, the empirical results are more in line with the proposition that highly price-conscious buyers make lower voluntary payments than consumers who are not so keen on low purchase prices. Hence, in practice, managers should reflect upon the degree to which their PWYW offerings primarily attract highly price-conscious buyers. If price strategists expect such a strong self-selection of bargain hunters, then it is usually economically better to operate with (regular) fixed prices instead of a PWYW approach.

\subsubsection{Satisfaction}

Service or product satisfaction captures the extent to which buyers believe that their quality expectations are met by the good sold. The literature typically posits: "Satisfaction plays a distinct role in PWYW pricing, as this mechanism allows consumers to immediately express their satisfaction or dissatisfaction with the product/service in terms of the amount they pay for it" (Stegemann, 2014, p. 30). However, an unmentioned prerequisite for significant impacts of satisfaction on the level of voluntary payments in PWYW settings is that consumers need to have already had the opportunity to experience the nature of the goods sold and pay for them after this experience. Otherwise, in contexts where customers pay before consumption satisfaction is likely to exert a clear influence on prices paid only if buyers are already very familiar with the peculiarities of the purchased service or product and have therefore formed a stable evaluation of the offering and/or its supplier. A total of nine studies find that buyer satisfaction is significantly positively correlated with prices paid voluntarily after consumption (see Table 1: Borck et al., 2006; Gautier \& Van der Klaauw, 2012; Kim et al., 2009, 2014a; León et 
al., 2012; Machado \& Sinha, 2012; Racherla et al., 2011; Riener, 2008; Schmidt et al., 2015). Solely, Drevs (2013) and Schons et al. (2014) observe no significant association between the two variables. Hence, overall it can be concluded that the link between buyer satisfaction with the products or services offered by a PWYW seller and the amounts paid after being served is sizable and significantly positive.

\subsubsection{General social preferences}

The key buyer attitudes related to beliefs about the way in which other persons should be treated in general and PWYW sellers in particular and which the PWYW literature often addresses as "social preferences" (Stegemann, 2014, p. 24), "underlying motives" (Natter \& Kaufmann, 2015, p. 154) or "payment motivation" (Kunter, 2015, p. 2355) of buyers are altruism, fairness concerns, desire to keep sellers in business and strategic intention to motivate suppliers in such a manner that they perform well in future sales encounters. Out of these constructs, altruism and fairness concerns have attracted the most attention.

Altruism deals with the general tendency of persons to help other individuals without expecting oneto-one compensatory returns from them (Huber et al., 2016). Six studies include evidence according to which altruism of buyers has significantly positive impacts on the magnitude of their voluntary payment (Gahler, 2016; Huber et al., 2013; Huber et al., 2014; Kim et al., 2009; Roy et al., 2016b; Santana \& Morwitz, 2011, 2013). Two analyses of Kim et al. (2009), who examine PWYW food sales in a restaurant and ticket sales in a cinema, as well as a study of Drevs (2013), who also looks at the sale of cinema tickets in a PWYW setting, report insignificant correlations between buyer altruism and PWYW prices paid. With the exception of the work of Kim et al. (2009) the studies which report significant correlations share the methodological weakness that they capture both altruistic attitudes as well as PWYW prices paid in a cross-sectional survey. Therefore, it may well be assumed that the detection of associations between the focal variables is mainly an artefact of the data collection approach, namely socalled "common method biases" (Podsakoff et al., 2009, p. 879): Survey participants who claim to be strongly altruistically motivated are likely to respond consistently in the same questionnaire by stating that they would also pay higher prices in fictitious PWYW sale contexts. However, in case of a real PWYW purchase they would actually pay a considerably lower amount.

Fairness concerns reflect attitudes of buyers according to which they are convinced that customers should respond to the goods they get from sellers by allocating a proportional return in the form of an "adequate" voluntary payment to the seller (Kim et al., 2009; Natter \& Kaufmann, 2015; Roy et al., $2016 \mathrm{~b}$ ). Nine publications using a total of 15 data sets report significantly positive associations between buyers' "preference for fairness" (Pöyry, 2015, p. L-26) and the level of PWYW prices paid (see Table 1; Drevs, 2013; Gahler, 2016; Kim et al., 2009, 2014 (study 2); Kunter, 2015; Lee et al., 2015; Santana \& Morwitz, 2015, 2016; Schons et al., 2014). Two data sets suggest insignificant associations (Kim et al., 2014a (study 1); Regner, 2015). With regard to the fairness construct it should also be taken into account that "common method biases" present in the relevant studies are likely to lead to inflated estimates of the size of correlations between fairness norms and voluntary payment amounts. In line with this proposition Regner (2015, p. 212) similarly concludes as follows: "There seems to be a discrepancy between the ex post reasoning for generous decisions and the actual motivations as customers expect fairness concerns to lead to generous payments, although there is no evidence in the data that these drive behavior."

\subsubsection{Interim conclusions}

Work exploring buyer characteristics as correlates of the magnitude of voluntary payments in PWYW contexts has so far yielded no consistent results with regard to the socio-demographic variables age, gender and income. Internal RP, price consciousness, satisfaction, altruism and fairness motives nearly always correlate significantly positively with the level of prices paid, but many investigations presumably contain inflated estimates of these associations because they are plagued with common method 
problems. In addition, the effects of the five last-mentioned factors on PWYW price levels can be qualified as being intuitively plausible, if not even as trivial. Finally, the accumulated knowledge concerning associations between the aforementioned psychographic buyer characteristics and the magnitude of voluntary payments in PWYW settings is not particularly useful in designing PWYW offerings in practice because sellers are simply unable to capture these attributes with reasonable effort.

Against this background, we conclude that additional research on buyer characteristics as potential drivers of the level of PWYW prices paid is not urgently needed. If researchers wish to further examine buyer characteristics in PWYW settings, then it is more promising to investigate associations between this class of variables and buyer decisions on whether to prefer a PWYW transaction to a fixed price purchase or not. So far such studies are entirely lacking.

\subsection{Seller characteristics}

The pertinent literature discusses the five characteristics of PWYW sellers shown in Figure 2 primarily in a qualitative manner as potential determinants of the amounts customers pay and seller decisions in favor of making PWYW offerings instead of a conventional fixed price sales strategy. In comparison, quantitative statistical results are rare to find. Accordingly, Regner \& Barria (209, p. 405), León et al. (2012, p. 411) and Schmidt et al. (2015, p. 1232) similarly argue that higher PWYW prices paid can be expected for sellers, who customers perceive as financially less strong and less profitable and not as a faceless large-scale corporation but rather as a locally rooted small- or at best medium-size trustworthy supplier/family business. Moreover, some authors stress that suppliers, who do not solely strive to maximize their profits but visibly operate in a pro-social and ethically exemplary way (e.g., through donating for charitable organizations) receive higher PWYW amounts than sellers, who do not possess such characteristics (Jung et al., 2014b; cf. section 3.4 below). The investigations of Gneezy et al. (2010), Kim et al. (2014a, study 2), Lee et al. (2015), Machado \& Sinha (2012), Marrett al. al. (2012), Roy et al. (2016b) and Santana \& Morwitz $(2011,2013)$ contain empirical results supporting this position. Similarly, Schlüter \& Vollan (2015) detect that in an honesty-based payment situation with fixed target prices (unobserved payments for flowers where the money is put into an honor box) buyers pay

significantly higher prices if the seller is described as a small family business compared to a seller profile as a large corporate business. In contrast, Park et al. (2016) find that a rate schedule including PWYW and a charity donation results in significantly lower payments per customer than a fixed price scheme.

All in all, the empirical evidence thus confirms the proposition that in PWYW contexts buyers unconsciously take into their (mental) calculation whom they support or harm by paying a high or low price, respectively (see Table 1). Moral concerns against a low price are put aside or reversely gain behavioral relevance if sellers are qualified as financially robust and, more generally, as unlikable or as financially weak and as likable, respectively. With a view to using the PWYW approach in practice, the results concerning PWYW seller characteristics imply the following: This price setting procedure is especially worth to be considered by smaller companies with strong social ties at their business locations and long-term business relationships to a loyal customer base than by organizations with the opposite attributes. From a scholarly perspective, it is vital that future research provides more fine-grained analyses of the effects of precisely defined supplier characteristics (e.g., corporate size, age, profitability and credibility) on the probability that PWYW offerings are taken up at all by prospective customers and on the prices paid in the subgroup of all buyers, who do not avoid a PWYW offering.

\subsection{Characteristics of the goods offered}

Effects of characteristics of the goods offered under PWYW conditions on customer take-up rates and the magnitude of voluntarily paid prices are also scarcely examined in PWYW research and, if at all, 
primarily in qualitative terms. Out of the sales object-related attributes listed in Figure 2, the absolute fixed prices, which are generally charged for a certain category of goods in the market and frequently labeled as "product value" (Pöyry, 2015, p. L-27; Stegemann, 2014, p. 27), the variable unit costs and the total unit costs still have achieved the most attention of PWYW researchers. The research results quite consistently suggest that normal absolute fixed prices of products or services significantly positively correlate with the absolute amount paid under PWYW conditions and are significantly negatively correlated with the relative PWYW price paid, which is the ratio of voluntary payments amounts to standard fixed market prices of the goods studied (see Table 1; Gahler, 2016; Gautier \& Van der Klaauw, 2012; Jang \& Chu, 2012; Kim et al., 2014a; León et al., 2012; Machado \& Sinha, 2012; Mak et al., 2015; Mills, 2013). In a similar vein, the (absolute) magnitude of voluntarily paid prices increases with the variable and average unit costs of the goods sold in a PWYW context in case that buyers are informed about these costs in advance of their price setting choice (Greiff et al., 2014; Krämer et al., 2015; Riener, 2008; Schmidt et al., 2015).

The explanatory power of these results should, however, be put into perspective due to the fact that they were almost without exception generated in samples of customers who were expectedly confronted with PWYW offerings. Therefore, a deliberate self-selection of buyers in favor of a PWYW setting was impossible. Gautier \& Van der Klaauw (2012) are the only researchers who compared a subsample of buyers who consciously opted for a PWYW offering (hotel-stay) with customers who were unexpectedly involved in a PWYW sales situation. They observe a significantly positive correlation between the normal fixed market price of the service customers received and the voluntary payment level only in the subsample of participants for whom the PWYW offer was unforeseen but not in the subsample of buyers who specifically selected the PWYW setting.

Overall, the evidence on PWYW prices paid as a function of the common "market value" or the variable production costs of the goods sold corroborate the following theoretical explanation: In cases of goods that are normally sold at low absolute (fixed) prices and that generate low costs, buyers are inclined to make voluntary payments which are relatively high compared to the standard market value of the goods offered. Buyers do this because a generous or at least fair payment level improves their self-image so clearly that the resulting subjective incremental benefit exceeds the subjective costs which result from the insight to have not minimized payouts by setting a (moderately unfair) low price. On the other hand, in cases of goods with high absolute fixed prices/costs the image benefit of buyers resulting from a high voluntary payment to market value/price ratio tends to be smaller than their subjectively perceived costs resulting from not having minimized their payouts by setting the voluntary payment at a low (and unfair) level. In other words, the functional relationship between a good's fixed price/market value/costs on the one hand and the image benefits or, respectively, costs of overpayment of a high ratio between the voluntarily paid price and the fixed price/market value/costs of goods on the other hand should be concave or convex, respectively (cf. Jang \& Chu, 2012; Kahsay \& Samahita, 2015; Machado \& Sinha, 2012). In practice, the empirical results and the respective theoretical explanations mean that from the view of sellers it is for the most part profit-wise preferable to limit PWYW offerings to products and services normally sold at low absolute (fixed) prices and produced at low costs. It is exactly this type of goods that is without exception analyzed in empirical PWYW field studies of real (and not just hypothetical) purchases (see section 2.2 above).

Apart from customary (fixed) market prices and production costs of PWYW goods, effects of a "prosocial" or "ethical" connotation of the products or services offered on prices paid voluntarily are explored in a few investigations. The issue here is whether donations of parts of the sales prices of goods for charitable purposes or production and marketing of goods under morally acceptable conditions furnish products or services with an additional value component, which reaches beyond their pure functional utility (Newholm \& Shaw, 2007; Small \& Cryder, 2016). The main result of studies on PWYW offerings with pro-social or ethical elements is that the share of potential customers voting in favor of such products and services is smaller than the corresponding share for strictly commercial offerings. 
At the same time, however, in the subsample of people, who opted for the "special" offerings, voluntarily paid prices are significantly higher than the amounts paid for "normal" products and services in PWYW settings (Gneezy et al., 2010, 2012; Jung et al., 2014b; Perfecto et al., 2013, 2014; Roy et al., 2016a; Santana \& Morwitz, 2011, 2013; Thomas \& Gierl, 2014; Ven, 2012).

To sum up, to date empirical PWYW studies have devoted little attention to effects of the characteristics of the goods sold under PWYW conditions on various outcomes of this price setting method. Therefore, a considerable number of questions important for extending pricing theories and improving price setting in practice have not yet been addressed. For instance, from a theoretical viewpoint, it is to be expected that new products or services, for which consumers experience considerable difficulties in assessing their quality and which are sold under PWYW conditions, are purchased by a lower share of potential customers and are characterized by a larger variance of the prices paid voluntarily for them than established goods whose quality is well know to prospective buyers. The PWYW studies of Sleesman \& Conlon (2016) and Weisstein et al. (2016) contain some support for this proposition. The expected differences can be explained by information gaps and resulting uncertainty of consumers, who are heavily influenced by characteristics of the goods sold in a PWYW setting (Greiff et al., 2014). Consequently, more empirical tests of this proposition and other hypotheses related to the characteristics of PWYW goods are highly desirable.

\subsection{Market context characteristics}

Corporations, which sell goods under "true" PWYW conditions, typically operate in a market environment, in which competitors also offer comparable products or services at traditional (fixed) prices or based on other pricing methods which promote consumer participation in price setting (e.g., Name Your Own Price, auctions, see section 1 above). In free markets, consumer switching from PWYW suppliers to offers of competitors is the easier, the larger the number of competitors present in the same relevant geographical area and the higher the similarity between the goods sold by competitors and PWYW providers (Greiff \& Egbert, 2016; Stegemann, 2014). Such external conditions including, in particular, the intensity of competition or consumer transparency with regard to the availability of other sellers and their pricing policies can be subsumed under the generic label "market context" (see Figure 2).

Market context characteristics are largely ignored in the empirical PWYW literature. Exceptions are the laboratory experiments of Krämer et al. (2015) and Schmidt et al. (2015). They show that the presence of competitors using conventional fixed prices has a negative effect on the level of price that PWYW buyers pay. Furthermore, they find the PWYW suppliers can push fixed price competitors completely out of a market.

In light of the neglect of market context conditions in prior PWYW research, future studies should take a much closer look at the effects of such factors on sales volumes and prices paid in PWYW contexts. In practice, the sparsely available evidence on the role of market context characteristics in PWYW settings already now implies that a general economic principle according to which sales and profit prospects of a company deteriorate with more intense competition, still remains fully in force even if sellers resort to the PWYW method in setting their prices.

\section{Customer perceptions of PWYW schemes}

By far the largest part of empirical work on PWYW follows the stimulus-response paradigm. This means that researchers explore how the (blocks of) variables discussed in the preceding sections 3.1 to 3.5 directly affect individual level outcome criteria such as offer acceptance rates or the magnitude of voluntarily paid amounts. Customer perceptions of PWYW schemes are hardly ever addressed. An 
explanation for this approach is that investigations assume consistently positive customer perceptions and preferences in favor of the innovative PWYW price setting method in spite of its low use frequency in practice. In line with this presumption Kim et al. (2009) find that $87 \%$ of the customers of a restaurant selling meals under PWYW conditions stated in a survey that they prefer the PWYW approach over binding price specifications imposed by sellers. Nevertheless, the neglect of customer perceptions and preferences concerning the PWYW method is regrettable because it makes it more difficult to understand and predict behavioral customer reactions to PWYW offerings in general and to various design characteristics of this price setting approach in particular. Thus, Figure 2 includes a block of variables titled "customer perceptions of PWYW schemes and their initiators", even though such perceptual facets are rarely covered in earlier research.

An exception is the work of Kim et al. (2014b). They gave product samples (razor blades) to one group of consumers and asked the people to voluntarily pay for them as much as they wanted (including 0 ). Another group of consumers received the sample for free. The PWYW group rated the sales promotion measure significantly better in terms of its entertainment value and innovativeness and significantly worse with regard to its saving potential and personal effort caused by the measure than the consumer group with the free of charge sample. A second field study, which was also conducted by Kim et al. (2014b) and focused on a professionally produced portrait photo, reveals similar results: Fixed discounts or free sample price settings outperformed the PWYW approach in terms of the personal effort of participating in the promotion as perceived by customers.

The studies of Gneezy et al. (2010), Machado \& Sinha (2012), Riener (2008), Santana \& Morwitz $(2011,2013)$ and Schmidt et al. (2015) contain additional mainly casuistic and qualitative evidence regarding the higher "cognitive effort" (Mendoza-Abarca \& Mellema, 2016, p. 120) triggered by the PWYW method in comparison with fixed prices. The reason for the higher effort imposed on consumers in a PWYW setting is that buyers have to think more for themselves about a price which fairly factors in currently charged market prices as well as the costs and interests of sellers. Taken together, the six publications just cited suggest that the extra cognitive effort combined with consumer uncertainties regarding the "appropriate" voluntary payment level and the seller motives underlying their PWYW offerings jointly decrease the attractiveness of PWYW price setting in the eyes of consumers. Hence, it is quite likely that in many PWYW application cases a significant share of consumers likes the established fixed price approach more than the PWYW method and therefore abstains from entering into a PWYW sales situation.

The few empirical results with respect to perceptions of PWYW schemes by consumers and the effects of an introduction of the PWYW method on consumer perceptions of the seller (= image) are contradictory. On the one hand, Stegemann (2014) observes that consumers evaluate sellers (restaurants, hair salons) significantly more positive if they use PWYW schemes instead of the fixed price approach. This is in contrast to results of Reese $(2012,2013)$, who finds no difference in perceived price fairness between consumers, who buy an entry ticket for a sports event under PWYW conditions and their counterparts, who receive a fixed price offering. Jostrup \& Salic (2015) report that customer attitudes towards a product (pear juice) do not vary depending on whether the product is offered under PWYW conditions or is given away for free. Finally, Mills (2013) detects that consumers with a positive attitude towards the PWYW method are significantly less likely to pay nothing for the download of a computer game than buyers with a negative attitude towards PWYW price setting.

So far, Gahler (2016) is the only researcher who analyzed how customer perceptions of PWYW schemes are influenced by attributes of their design and characteristics of the goods sold in a PWYW context. According to his data buyers rate the fairness of PWYW offerings as being better if sellers present external RP to help buyers in choosing appropriate prices and if the good offered has low variable production costs and therefore has a typical market price which is low in absolute terms. 
Within the research stream addressing perceptions of PWYW customers, studies on customer self-assessments of the importance of various "motivation-related payment factors" (Kunter, 2015, p. 2347) cover a special niche. According to such examinations, buyers name fairness considerations, attempts to avoid feelings of guilt or shame, product or service satisfaction, constrained financial resources, desires to make a bargain and external RP as factors that they believe to have the strongest impacts on their decisions regarding the prices paid voluntarily (Dorn \& Suessmair, 2016; Kunter, 2015; Regner, 2015). The work of Regner (2015), however, contains strong indications in support of the position that customer self-ratings of the importance of various payment motives in determining PWYW prices are correlated only very weakly with the amounts effectively paid.

In summary, research on customer perceptions of PWYW schemes with regard to various dimensions such as psychological costs of price choices under time pressure and uncertainties or presumed seller motives for using the PWYW method is still in its infancy. The number of already existing relevant investigations is not only small. Rather, their focus on hypothetical purchases of students gives strong reasons to question the external validity of this stream of research. Accordingly, at present, it is very difficult to derive sound statements with regard to the value distributions for various dimensions reflecting customer perceptions of PWYW schemes. Similarly, it is impossible to make empirically substantiated recommendations for practitioners on how to influence customer perceptions of PWYW schemes as a prerequisite for improving the economic success prospects of such schemes. This means that customer perceptions of PWYW schemes should play a very prominent role in future empirical work.

\section{Evaluation of economic outcomes of PWYW pricing}

The criteria for assessing direct economic outcomes of an implementation of PWYW pricing for sellers used most frequently by PWYW researchers are (1) the prices paid voluntarily, (2) the number of units sold or customers served and (3) the resulting revenues generated in the PWYW application period (see Figure 2). Values of these three criteria captured for periods during which prices are exclusively fixed by sellers are normally called on as yardsticks required to derive a comprehensive evaluation of the economic success level of PWYW pricing. In general, "one-shot" analyses that merely examine a single and narrow time window by far outweigh work covering the development of economic success measures over longer periods.

The evaluation results of field studies, which contain behavioral data on PWYW prices paid voluntarily for real purchases and compare them with common fixed market prices, yield the following overall picture (Bourreau et al., 2015; Drevs, 2013; Gautier \& Van der Klaauw, 2012; Gneezy et al., 2010, 2012; Kim et al., 2009, 2010a, 2010b, 2014a, 2014b; León et al., 2012; Machado \& Sinha, 2012 (study 3); Regner, 2015; Riener \& Traxler, 2012):

- Only a very small portion of buyers pays nothing or more than the standard fixed price for the good, respectively.

- The majority of buyers pays less than the standard fixed price so that the average payment per unit/ customer in a PWYW setting is lower than the regular fixed market price for the good.

- Notwithstanding that PWYW price averages are often found to be below the standard fixed prices for various categories of goods, the likelihood is quite substantial that PWYW pricing may result in revenue increases in comparison to periods during which sellers charged fixed prices. This implies that the PWYW method deters few customers and attracts many new accounts which in turn leads to raises in the number of customer that are so large that they more than offset the negative revenue effect of lower payments per customer or purchase. 
Overall, empirical evaluations of the economic outcomes of PWYW pricing draw a cautiously optimistic picture with regard to the immediate financial advantages of this price setting method in comparison with standard fixed prices. A significant exception is the work of León et al. (2012), according to which customers of a Spanish holiday tour operator on average merely paid $7.9 \%$ of the regular prices for holiday trip packages offered under PWYW conditions. However, the tour operator designed the PWYW offers as a time-limited sales promotion measure. This way, increases in the number of packages sold were impossible and customers were encouraged to classify the offers as a temporary marketing action in the course of which very low payments would not seriously harm the seller. However, even empirical investigations, which rate certain PWYW application cases as being economically successful, consistently emphasize that a customized design of the method adapted to the individual use situation combined with a careful selection of the targeted consumer group and of the goods offered are crucial for ensuring that the economic outcomes of PWYW pricing are favorable relative to the results of a fixed price setting approach.

The long-term development of the amounts paid voluntarily in PWYW applications is an important driver of the sustainability of economic PWYW advantages relative to a situation, in which sellers set fixed prices. Research results with regard to such changes over time are contradictory. Based on intraindividual comparisons of PWYW prices paid at subsequent purchase events Gravert (2014), Regner \& Barria (2015) and Schons et al. (2014) observe significant decreases in voluntary payment amounts over the course of time. In contrast to that, Jung et al. (2014b) report that the magnitude of voluntary payments, which customers make at consecutive purchases of the same type of goods, remains constant. Looking at price averages measured at various points in time, Riener \& Traxler (2012) and Schons et al. (2014) find that the monthly means of the voluntary payments sellers record over 24 or two months, respectively, drop. On the other hand, Kim et al. (2010b) and Mills $(2011,2013)$ note that the prices buyers pay on average grow during 12 months or 14 days, respectively. Finally, Regner \& Barria (2009) detect no significant differences between the monthly mean PWYW amounts which an online seller of music tracks receives over an 18-months period.

Considering the mixed empirical evidence generalizing reliable conclusions, with regard to the intertemporal stability of the amount of voluntary payments at the within and between customer level, are currently impossible. Therefore, additional research is sorely needed which details the factors causing significant within and between individual changes in the prices buyers voluntarily pay over time.

A few authors point out that evaluations of the economic outcomes of PWYW pricing should include criteria which measure less immediate financial and non-financial effects of the method as a supplement to variables reflecting its direct economic results (Stegemann, 2014; Natter \& Kaufmann, 2015). The most prominent "indirect" financial outcomes of PWYW pricing are additional revenues that a supplier generates through stimulating demand for other and potentially more expensive products or services which typically complement the goods sold at PWYW (e.g., drinks served with a meal in a restaurant). The empirical literature occasionally mentions such cross- and up-selling effects of the PWYW method (Gneezy et al., 2010; Kim et al., 2009, 2010b, 2014a, 2014b; Schmidt et al., 2015; Steiner, 1997). However, these effects have not yet been the focus of systematic empirical investigation.

Behavioral and attitudinal customer reactions, which are captured after an isolated PWYW purchase or a series of transactions and which go beyond the choice of a payment amount, can be considered as prime non-financial PWYW outcomes. For instance, it is plausible that deliberate or incidental customer encounters with PWYW may influence buyer satisfaction with a good after its purchase, seller image in the eyes of the buyers, follow-up purchases and seller recommendations communicated by buyers to other consumers (Kim et al., 2009, 2014a, 2014b; Natter \& Kaufmann, 2015; see also Figure 2 ). This class of criteria has also been almost never taken into account in earlier empirical PWYW research. Finally, hardly any empirical study has yet addressed effects that the use of PWYW by one specific supplier has on financial and non-financial outcomes of its competitors (cf. Figure 2). 
In conclusion, the literature review reveals that research systematically evaluating economic outcomes of PWYW pricing is scarce and mostly limited to short-term effects on the seller's number of units sold or customers served and revenues. On balance, economic evaluations of economic PWYW outcomes in comparison to those of fixed prices or free give-aways are more often positive than negative. One reason for this may be that unsuccessful PWYW trials do not find their way into the published literature. In any event, future PWYW evaluation studies are required that include additional economic outcome criteria supplementing established unit sales and revenue measures and that track the development of success variables over long time periods.

\section{Perspectives}

The present article reviews the results of 72 PWYW research contributions published between January 2006 and September 2016 which contain a total of 97 independent empirical data sets. A comprehensive conceptual framework is used to organize the analysis of the literature. Detailed findings of the review do not have to be repeated in this concluding section. Instead, we highlight more general implications of the current state of empirical PWYW studies which are of fundamental importance for future scholarly research in the PWYW field and practical applications of this price setting approach in corporations.

In terms of future research, content-related and methodological perspectives need to be differentiated. According to our review, the most promising content-related improvement of empirical PWYW work is likely to be achieved by extending the stimulus-response paradigm currently underlying most research in the direction of the stimulus-organism-response approach. Future investigations should not only explore how specific characteristics of the procedural PWYW design, suppliers, buyers, goods sold and the market context affect the acceptance rate of PWYW offers among prospective customers and the magnitude of the price paid. Instead, they should additionally integrate perceptions of the PWYW approach and its initiator as potential drivers of economic PWYW outcomes both in the group of consumers, who purchase under PWYW and of their counterparts, who reject this pricing method (see section 4).

As far as methodology is concerned, when choosing statistical analytical techniques, earlier PWYW investigations have not sufficiently taken into account that their techniques actually ought to be able to model two distinct consumer choices, namely: (1) binary fundamental decision about whether to purchase the PWYW good or not (yes or no) and (2) selection of the amount paid voluntarily (Regner, 2014, p. 197). Thus, a two-step analysis is desirable. In a first step, researchers should, for example with the help of binary Probit or Logit regression techniques, explore which variables significantly contribute to discriminating PWYW buyers from avoiders. Second, within the subgroup of PWYW buyers variables significantly contributing to explaining variance in the prices paid voluntarily should be identified, for instance by means of Ordinary Least Squares or "truncated" regression techniques (cf. Green, 2013, chapter 19). As part of the second step, it would be interesting to additionally work out to what extent variables, which significantly contribute to distinguishing buyers who pay nothing from consumers who pay a price $>0$, are also suited to predict the voluntary payment amounts in the subgroup of buyers paying more than zero.

With a view to implementing the PWYW approach in practice, the preceding literature review allows to derive a number of propositions on constraints whose fulfillment increases the likelihood that sales under PWYW become economically viable to suppliers. Accordingly, from a seller perspective, PWYW offers seem to be particularly suitable in case that

- the goods sold cause low variable/direct costs and are otherwise marketed at low absolute standard fixed prices; 
- the supplier has, at least temporarily, significant quantities of unused production capacities;

- the supplier is a small business which is socially rooted at its sales locations;

- the supplier targets less price-conscious consumers who are convinced that the seller has fair intentions in reverting to PWYW, place great emphasis on acting fairly towards their suppliers and are satisfied with the purchased good;

- external RP are quoted only if it is highly likely that addressed consumers qualify them as being credible or reasonable, respectively;

- the anonymity of buyers or their personal encounter with seller representatives or other people are not artificially reduced or increased, respectively, compared with sales contexts in which the focal category of goods is available at fixed prices.

The present review of the empirical PWYW literature already allowed to draw a number of significant, albeit preliminary conclusions for future investigations and applications of this price setting method in corporations. Nevertheless, noting the large number of research gaps identified above, it is evident that there are many different promising starting points for theory-grounded empirical PWYW studies. Hopefully, the present analysis of the state of evidence is helpful in inspiring such additional work.

\section{References $^{1}$}

Armstrong Soule, C.A., \& Madrigal, R. (2015)* . Anchors and norms in anonymous pay-what-youwant pricing contexts. In: Journal of Behavioral and Experimental Economics, 57, 167-175.

Atlas, S. (2015) ${ }^{*}$. Rebate what you want. In: Advances in Consumer Research, 43, 10.

Azar, O.H. (2007). The social norm of tipping: A review. In: Journal of Applied Social Psychology, 37, 380-402.

Bekkers, R., \& Wiepking, P. (2011). A literature review of empirical studies of philanthropy: Eight mechanisms that drive charitable giving. In: Nonprofit and Voluntary Sector Quarterly, 40, 924973.

Bertini, M., \& Koenigsberg, O. (2014). When customers help set prices. In: MIT Sloan Management Review, 55(4), 57-64.

Bondos, I., \& Lipowski, M. (2016) * Effectiveness of PWYW - Are there interchannel differences? In: Proceedings of the Joint International Conference 2016 Management, Knowledge and Learning, May 25-27, Timisoara. Available at http://www.toknowpress.net/ISBN/978-961-6914-16-1/papers/ML16-033.pdf (accessed November 16, 2016).

Borck, R., Frank, B., \& Robledo J.R. (2006) * An empirical analysis of voluntary payments for information goods on the Internet. In: Information Economics and Policy, 18, 229-239.

Bourreau, M., Dogan, P., \& Hong, S. (2015)* . Making money by giving it for free: Radiohead's prerelease strategy for In Rainbows. Information Economics and Policy, 37, 77-93.

Chao, Y., Fernandez, J., \& Nahata, B. (2015). Pay-what-you-want pricing: Can it be profitable? In: Journal of Behavioral and Experimental Economics, 57, 176-185.

Chen, Z., \& Liang, X. (2014). The performance of pay-as-you-wish pricing with relational and forwardlooking customers. In: Proceedings of the 11th International Conference on Service Systems and Service Management (ICSSSM), June 25-27, Beijing. Available at http://ieeexplore.iee.org/ stamp/stamp.jsp?tp=\&arnumber=6943418 (accessed November 16, 2016).

$1 \quad$ Entries marked with an asterisk behind their year of publication are the (72) empirical contributions whose analysis lies at the heart of the present article. A table with a brief profile of each of these papers is available on request from the author. 
Dorn, T., \& Suessmair, A. (2016) ${ }^{*}$. Is it really worth it? A test of pay-what-you-want pricing strategies in a German consumer behavior context. In: Global Business and Economics Review, 18, 82-100.

Drevs, F. (2013)* The challenge of the unknown - The effect of pay-what-you-want on the market success of publicly subsidized films. In: Zeitschrift für öffentliche und gemeinwirtschaftliche Unternehmen, 36, 255-270.

El Harbi, S., Grolleau, G., \& Bekir, I. (2014). Substituting piracy with a pay-what-you-want option: Does it make sense? In: European Journal of Law and Economics, 37, 277-297.

Engel, C. (2011). Dictator games: A meta study. In: Experimental Economics, 14, 583-610.

Fay, S. (2004). Partial-repeat-bidding in the name-your-own-price channel. In: Marketing Science, 23, 407-418.

Fernandez, J., \& Nahata, B. (2009). Pay what you like. Louisville University: MPRA Paper No. 16265. Available at http://mpra.ub.uni-muenchen.de/16265/ (accessed November 16, 2016).

Gahler, M. (2016)* Pay-What-You-Want im Internet. Wiesbaden: Springer Gabler.

Gautier, P.A., \& Van der Klaauw, B. (2012)* . Selection in a field experiment with voluntary participation. In: Journal of Applied Econometrics, 27, 63-84.

Gneezy, A., Gneezy, U., Nelson, L.D., \& Brown, A. (2010)*. Shared social responsibility: A field experiment in pay-what-you-want pricing and charitable giving. In: Science, 329, 325-327.

Gneezy, A., Gneezy, U., Riener, G., \& Nelson, L.D. (2012)*. Pay-what-you-want, identity, and selfsignaling in markets. In: Proceedings of the National Academy of Sciences, 109, 7236-7240.

Gravert, C. $(2014)^{*}$. Pride and patronage - The effect of identity on pay-what-you-want prices at a charitable bookstore. Aarhus University: Economics Working Papers 2014-04. Available at http:// pure.au.dk/portal/files/68738741/wp14_04.pdf (accessed November 16, 2016).

Greene, W.H. (2013). Econometric analysis (7th ed.). New York: Pearson.

Greiff, M., \& Egbert, H. (2016). A survey of the empirical evidence on PWYW pricing. Justus-Liebig University Giessen and Anhalt University of Applied Sciences: MPRA Paper No. 68693. Available at http://mpra.ub.uni-muenchen.de/68693/ (accessed November 16, 2016).

Greiff, M., Egbert, H., \& Xhangolli, K. (2014). Pay what you want - But pay enough! Information asymmetries and PWYW pricing. In: Management \& Marketing, 9, 193-204.

Hilbert, L.P., \& Suessmair, A. (2015)* . The effects of social interaction and social norm compliance in pay-what-you-want situations. In: American Journal of Industrial and Business Management, 5, 548-556.

Hildenbrand, A., Pabst, E., Schilling, U., Bitsch, L., \& Hanf, J.H. (2016)* . Der Pay-What-You-WantMechanismus als Preissetzungsmechanismus für Weinverkostungen. Paper presented at the Annual Meeting of the Austrian Society of Agricultural Economics, September 15-16, Vienna.

Huber, F., Appelmann, E., \& Lenzen, M. (2016). Pay-What-You-Want. Lohmar: Eul.

Huber, F., Lenzen, M., Meyer, F., \& Appelmann, E. (2013)* The role of altruistic and egoistic motivations in pay what you want situations. In: Kubacki, K. (Ed.), Ideas in Marketing: Finding the New and Polishing the Old - Proceedings of the 2013 Academy of Marketing Science (AMS) annual conference, New York: Springer, 28-31.

Huber, F., Meyer, F., \& Appelmann, E. (2014) ${ }^{*}$. The moderating role of loyalty and satisfaction on the effectiveness of altruistic and egoistic motivation in pay what you want situations. Beitrag zur $A s-$ sociation of Consumer Research European Conference.

Isaac, R.M., Lightle, J.P., \& Norton, D.A. (2015). The pay-what-you-want business model: Warm glow revenues and endogenous price discrimination. In: Journal of Behavioral and Experimental Economics, 57, 215-223.

Jang, H., \& Chu, W. (2012)* . Are consumers acting fairly toward companies? An examination of paywhat-you-want pricing. In: Journal of Macromarketing, 32, 348-360. 
Johnson, J.W., \& Cui, A.P. (2013) ${ }^{*}$. To influence or not to influence: External reference price strategies in pay-what-you-want pricing. In: Journal of Business Research, 66, 275-281.

Jostrup, E., \& Salic, E. (2015)* Pay for it and love it more: A comparative study in marketing psychology between the two campaign methods pay what you want and free. Bachelor psychology course student paper, Lund University, Department of Psychology. Available at http://lup.lub.lu.se /luur/download?func $=$ downloadFile $\&$ recordOId $=7365833 \&$ fileOId $=7365971$ (accessed November $16,2016)$.

Jung, M.H., Nelson, L.D., Gneezy, A., \& Gneezy, U. (2014a). Paying more when paying for others. In: Journal of Personality and Social Psychology, 107, 414-431.

Jung, M.H., Nelson, L.D., Gneezy, A., \& Gneezy, U. (2014b) ${ }^{*}$. Signaling virtue: Charitable behavior under consumer elective pricing. SSRN paper 2447960. Available at http://papers.ssrn.com/sol3/ papers.cfm?abstract_id=2447960\&download=yes (accessed November 16, 2016).

Jung, M.H., Perfecto, H., \& Nelson, L.D. (2016)* . Anchoring in payment: Evaluating a judgmental heuristic in field experimental settings. In: Journal of Marketing Research, 53, 354-368.

Kahsay, G.A., \& Samahita, M. (2015). Pay-what-you-want pricing schemes: A self-image perspective. In: Journal of Behavioral and Experimental Finance, 7, 17-28.

Kim, J.-Y., Kaufmann, K., \& Stegemann, M. (2014a)* . The impact of buyer-seller relationships and reference prices on the effectiveness of the pay what you want pricing mechanism. In: Marketing Letters, 25, 409-423.

Kim, J.-Y., Natter, M., \& Spann, M. (2009) ${ }^{*}$. Pay what you want: A new participative pricing mechanism. In: Journal of Marketing, 73 (1), 44-58.

Kim, J.-Y., Natter, M., \& Spann, M. (2010a)* Pay-what-you-want - Praxisrelevanz und Konsumentenverhalten. In: Zeitschrift für Betriebswirtschaft, 80, 147-169.

Kim, J.-Y., Natter, M., \& Spann, M. (2010b) ${ }^{*}$. Kish: Where customers pay as they wish. In: Review of Marketing Science, 8 (article 3), 1-12.

Kim, J.-Y., Natter, M., \& Spann, M. (2014b) ${ }^{*}$. Sampling, discounts or pay-what-you-want: Two field experiments. In: International Journal of Research in Marketing, 31, 327-334.

Krämer, F., Schmidt, K.M., Spann, M., \& Stich, L. (2015)* . Delegating pricing power to customers: Pay what you want or name your own price. Centre for Economic Policy Research London: Discussion Paper No. 10605. Available at http://www.cepr.org/active/publications/discussion_papers/ dp.php?dpno=10605 (accessed November 16, 2016).

Krawczyk, M., Kukla-Gryz, A., \& Tyrowicz, J. (2015)* . Pushed by the crowd or pulled by the leaders? Peer effects in pay-what-you-want. University of Warsaw: Faculty of Economic Sciences Working Papers No. 25/2015 (173). Available at http://www.wne.uw.edu.pl/files/1514/3872/2613/ WNE_WP173.pdf (accessed November 16, 2016).

Kunter, M. (2015)* ${ }^{*}$ Exploring the Pay-What-You-Want payment motivation. In: Journal of Business Research, 68, 2347-2357.

Kunter, M., \& Braun, D. (2013)* "“The price is up to you!” - “Oh no! What am I gonna do?” Customers' product category inexperience and belief about other customers' payments under pay-what-youwant conditions. In: European Journal of Management, 13 (2), 15-21.

Lee, S.R., Baumgartner, H., \& Pieters, R. (2011)*. Are you really paying what you wish? Interpersonal influences on price decisions. In: Advances in Consumer Research, 39, 540-541.

Lee, S.R., Baumgartner, H., \& Pieters, R. (2015)* . Are you really paying as little as possible? Constraints on consumers' self-interest seeking in participative pricing. Unpublished manuscript.

León, F.J., Noguera, J.A., \& Tena-Sánchez, J. (2012)* . How much would you like to pay? Trust, reciprocity and prosocial motivations in El trato. In: Social Science Information, 51, 389-417. 
Lynn, M. (1990). Choose your own price: An exploratory study requiring an expanded view of price's functions. In: Advances in Consumer Research, 17, 710-714.

Lynn, M., Flynn, S.M., \& Helion, C. (2013) ${ }^{*}$. Do consumers prefer round prices? Evidence from paywhat-you-want decisions and self-pumped gasoline purchases. In: Journal of Economic Psychology, 36, 96-102.

Machado, F., \& Sinha, R.K. (2012)* . The viability of pay what you want pricing. Manuscript submitted to Management Science. Available at http://ebape.fgv.br/sites/ebape.fgv.br/files/Working-Pape r-Fernando-Machado-Viability-of-Pay-What-you-Want-Pricing.pdf (accessed November 16, 2016).

Mak, V., Zwick, R., Rao, A.R., \& Pattaratanakun, J.A. (2015)*. "Pay what you want" as threshold public good provision. In: Organizational Behavior and Human Decision Processes, 127, 30-43.

Marett, K., Pearson, R., \& Moore, R.S. (2012)* . Pay what you want: An exploratory study of social exchange and buyer-determined prices of iProducts. In: Communications of the Association for Information Systems, 30 (article 10), 1-14.

Mazumdar, T., Raj, S.P., \& Sinha, I. (2005). Reference price research: Review and propositions. In: Journal of Marketing, 69 (4), 84-102.

Mendoza-Abarca, K.I., \& Mellema, H.N. (2016). Aligning economic and social value creation through pay-what-you-want pricing. In: Journal of Social Entrepreneurship, 7, 101-125.

Mills, P. (2011)* Economic and financial insights from a cross-cultural pay-what-you-want study. In: Proceedings of the 2011 Annual Meeting of the Academy of Behavioral Finance and Economics, September 21-23, Los Angeles. Available at https://p11.secure.hostingprod.com/@www.aobf. org/ssl/attachments/2011/ABF_2011_Proceedings_Book.pdf (accessed November 16, 2016).

Mills, P. (2013) ${ }^{*}$. Trust, reciprocity and fairness in a large scale pay what you wish experiment. In: Competitive Paper Session, Society for the Advancement of Behavioral Economics, SABE/IAREP/ ICABEEP conference, Atlanta. Available at http://apps.clayton.edu/SABE-IAREP-ICABEEP-Con ference/Papers/Download/26 (accessed November 16, 2016).

Mousazadeh, M., \& Izadkhah, M. (2015). The ultimatum game: A comprehensive literature review. In: Applied Mathematics in Engineering, Management and Technology, 3, 158-165.

Natter, M., \& Kaufmann, K. (2015). Voluntary market payments: Underlying motives, success drivers and success potentials. In: Journal of Behavioral and Experimental Economics, 57, 149-157.

Newholm, T., \& Shaw, D. (2007). Studying the ethical consumer: A review of research. In: Journal of Consumer Behaviour, 6, 253-270.

Park, S., Nam, S., \& Lee, J. (2016) ${ }^{*}$. Charitable giving, suggestion, and learning from others: PayWhat-You-Want experiments at a coffee shop. In: Journal of Behavioral and Experimental Economics, in press, DOI: http://dx.doi.org/10.1016/j.socec.2016.04.010.

Parvinen, P., Pöyry, E., \& Kaptein, M. (2013)* . Pay-what-you-want pricing - The impact of framing. Paper presented at the American Marketing Association Winter Marketing Educator Conference, February 15-17, Las Vegas, 110-121. Available at http://connection.ebscohost.com/c/articles/ 86740067/pay-what-you-want-pricing-impact-framing (accessed November 16, 2016).

Perfecto, H., Jung, M.H., \& Nelson, L.D., (2014)* . Precision aversion in pay-what-you-want pricing. In: Proceedings of the Annual Conference of the Society of Consumer Research, March 6-8, Miami. Available at http://www.myscp.org/pdf/conference\%20documents/SCP2014_Proceedings_04 282014.pdf (accessed November 16, 2016).

Perfecto, H., Jung, M.H., Nelson, L.D., Gneezy, A., \& Gneezy, U. (2013)* . Default effects under paywhat-you-want: Evidence from the field. In: Advances in Consumer Research, 41, 265-266.

Podsakoff, P.M., MacKenzie, S.B., Lee, J.-Y., \& Podsakoff, N.P. (2003). Common method biases in behavioral research: A critical review of the literature and recommended remedies. In: Journal of Applied Psychology, 88, 879-903. 
Pöyry, E. (2015). Pay-what-you-want pricing research: Review and propositions. In: Ahearne, M., \& Hughes, D.E. (Eds.), 2015 AMA Marketing Summer Educators' Conference "Improving Business Practice Through Marketing Insight”, August 14-16, Chicago, Vol. 26, L-23-L-31.

Pöyry, E., \& Parvinen, P. (2014)*. Pay-what-you-want - A field experiment on anonymity and reference price cues. In: Grewal, D., Roggeveen, A.L., \& Nordfält, J. (Eds.), Proceedings of the "Shopper Marketing \& Pricing Conference”, May 8-10, Stockholm, 18-19.

Pöyry, E., Parvinen, P., \& Kaptein, M. (2013) ${ }^{*}$. Using pay-what-you-want in new product pricing. In: Proceedings of the 2013 Aalto University-GAMMA Joint Symposium, April 26, Helsinki, 54-57.

Racherla, P., Babb, J.S., \& Keith, M.J. (2011)* Pay-what-you-want pricing for mobile applications: The effect of privacy assurances and social information. In: Proceedings of the 4th Information Systems Applied Research Conference, November 3-6, Wilmington. Available at http://proc. conisar.org/2011/pdf/1833.pdf (accessed November 16, 2016).

Reese, J.D. (2012) * Participatory pricing in sport: An examination of name-your-own-price and paywhat-you-want. Dissertation Texas A\&M University.

Reese, J.D. (2013) ${ }^{*}$. Participatory pricing in sport: An examination of name-your-own-price and paywhat-you-want. Stephen F. Austin State University at Nacogdoches, Texas, Faculty Publications Paper 12. Available at http://scholarworks.sfasu.edu/cgi/viewcontent.cgi?article=1011\&conte $\mathrm{xt}=$ management_facultypubs (accessed November 16, 2016).

Regner, T. (2014). Social preferences? Google Answers! In: Games and Economic Behavior, 85, 188209.

Regner, T. (2015)* Why consumers pay voluntarily: Evidence from online music. In: Journal of Behavioral and Experimental Economics, 57, 205-214.

Regner, T., \& Barria, J.A. (2009)* . Do consumers pay voluntarily? The case of online music. In: Journal of Economic Behavior \& Organization, 71, 395-406.

Regner, T., \& Riener, G. (2012) ${ }^{*}$. Voluntary payments, privacy and social pressure on the Internet: A natural field experiment. University of Dusseldorf: Institute for Competition Economics Discussion Paper No. 82. Available at https://www.econstor.eu/dspace/bitstream/10419/68231/1/7343578 42.pdf (accessed November 16, 2016).

Riener, G. (2008)*. How free is your lunch: Evidence from an "Eat-as-you-want-pay-as-you-wish", restaurant. University of Essex. Available at http://deewan.at/wp-content/uploads/2012/02/Riener. pdf (accessed November 16, 2016).

Riener, G., \& Traxler, C. (2012)* Norms, moods, and free lunch: Longitudinal evidence on payments from a pay-what-you-want restaurant. In: Journal of Socio-Economics, 41, 476-483.

Roy, R. (2015)* . An insight into pay-what-you-want pricing. In: Marketing Intelligence \& Planning, 33, 733-748.

Roy, R., Rabbanee, F.K., \& Sharma, P. (2016a) ${ }^{*}$. Exploring the interactions among external reference price, social visibility and purchase motivation in pay-what-you-want pricing. In: European Journal of Marketing, 50, 816-837.

Roy, R., Rabbanee, F.K., \& Sharma, P. (2016b)* Antecedents, outcomes, and mediating role of internal reference prices in pay-what-you-want pricing. In: Marketing Intelligence \& Planning, 34, $117-$ 136.

Saccardo, S., \& Gneezy, A. (2014)* . Want vs. can: Self-signaling via participative price appeals. In: Proceedings of the Annual Conference of the Society of Consumer Research, March 6-8, Miami. Available at http://www.myscp.org/pdf/conference\%20documents/SCP2014_Proceedings_042820 14.pdf (accessed November 16, 2016).

Saccardo, S., Li, C., Samek, A., \& Gneezy, A. (2015) ${ }^{*}$. Shifting mindset in consumer elective pricing. In: Advances in Consumer Research, 43, 7-8. 
Santana, S., \& Morwitz, V.G. (2011)* . Buying what you can get for free: How self-presentation motives influence payment decisions in pay-what-you-want contexts. In: Advances in Consumer Research, 39, 253.

Santana, S., \& Morwitz, V.G. (2013)* . We're in this together: How sellers, social values, and relationship norms influence consumer payments in pay-what-you-want contexts. Manuscript submitted to Journal of Marketing. Available at http://www8.gsb.columbia.edu/programs/sites/programs/ files/marketing/seminar_papers/paper_santana_fa13.pdf (accessed November 16, 2016).

Santana, S., \& Morwitz, V.G. (2015) ${ }^{*}$. Because we're partners: How social values and relationship norms influence consumer payments in pay-what-you-want contexts. In: Advances in Consumer Research, 43, 8-9.

Santana, S., \& Morwitz, V.G. (2016)* ${ }^{*}$ Because we're partners: How social values and relationship norms influence consumer payments in pay-what-you-want contexts. Unpublished manuscript submitted to Journal of Marketing Research.

Schlüter, A., \& Vollan, B. (2015). Flowers and an honour box: Evidence on framing effects. In: Journal of Behavioral and Experimental Economics, 57, 186-199.

Schmidt, K.M., Spann, M., \& Zeithammer, R. (2015)*. Pay what you want as a marketing strategy in monopolistic and competitive markets. In: Management Science, 61, 1217-1236.

Schons, L.M., Rese, M., Wieseke, J., Rasmussen, W., Weber, D., \& Strotmann, W.-C. (2014)* . There is nothing permanent except change - Analyzing individual price dynamics in "pay-what-you-want" situations. In: Marketing Letters, 25, 25-36.

Schröder, M., Lüer, A., \& Sadrieh, A. (2015) ${ }^{*}$. Pay-what-you-want or mark-off-your-own-price - A framing effect in customer-selected pricing. In: Journal of Behavioral and Experimental Economics, 57, 200-204.

Sleesman, D.J., \& Conlon, D.E. (2016) )* Encouraging prosocial decisions: The role of fairness salience and uncertainty. In: Journal of Behavioral Decision Making, in Press, DOI: 10.1002/bdm. 1970.

Small, D.A., \& Cryder, C. (2016). Prosocial consumer behavior. In: Current Opinion in Psychology, 10, 107-111.

Stegemann, M. (2014)* Success factors of pay what you want pricing. Dissertation University of Muenster.

Steiner, F. (1997). Optimal pricing of museum admission. In: Journal of Cultural Economics, 21, $307-$ 333.

Thomas, S., \& Gierl, H. (2014) ${ }^{*}$. Pay what you want: How to affect the price consumers are willing to pay. In: Proceedings of the 13th International Conference on Research in Advertising, June 26-28, Amsterdam.

Tudón, J.F. (2015). Pay what you want because I don't know how much to charge you. Economic Letters, 137, 41-44.

Veit, K., \& Ammermann, S. (2013)* . Why would you pay? An exploratory study in pay-what-you-want pricing. Masters Thesis, Lund University, School of Economics and Management. Available at http://lup.lub.lu.se/luur/download?func=downloadFile\&recordOId=3799386\&fileOId=3799387 (accessed November 16, 2016).

Ven, L. van de $(2012)^{*}$. Fair play via fair pay: A PWYW pricing strategy for fairtrade. Master Thesis, Erasmus University, Rotterdam School of Management. Available at http://www.rsm.nl/file admin/Images_NEW/Events/Sustainability_Forum/Thesis_Laura_van_de_Ven_RSM_2012_2013. pdf (accessed November 16, 2016).

Waskow, S., Markett, S., Montag, C., Weber, B., Trautner, P., Kramarz, V., \& Reuter, M. (2016) * Pay what you want! A pilot study on neural correlates of voluntary payments for music. In: Frontiers in Psychology, 7, in press, DOI: http://dx.doi.org/10.3389/fpsyg.2016.01023. 
Weisstein, F.L., Kukar-Kinney, M., \& Monroe, K.B. (2016) ${ }^{*}$. Determinants of consumers' response to pay-what-you-want pricing strategy on the Internet. In: Journal of Business Research, 69, 43134320.

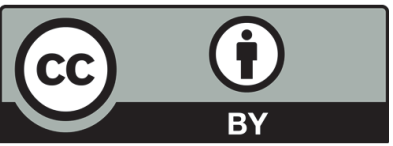

(C) 2016 by the authors; licensee Growing Science, Canada. This is an open access article distributed under the terms and conditions of the Creative Commons Attribution (CC-BY) license (http://creativecommons.org/licenses/by/4.0/). 